\title{
Editorial
}

\section{Oral surgery recognized as a surgical specialty in its own right}

\author{
Laurent Devoize* \\ Université Clermont Auvergne, CHU Clermont-Ferrand, INSERM, Neuro-Dol, 63000 Clermont-Ferrand, France
}

(Received: 14 June 2021, accepted: 14 June 2021)

The current National Academy of Surgery, heir to the Royal Academy of Surgery, is the oldest surgical institution in France. Founded in 1731 by Georges Mareschal, Louis XV's first surgeon and by François La Peyronie, his successor, it will be dissolved during the Revolution, then will be reborn in 1843 at the initiative of several surgeons, first under the name of Society of Surgery de Paris, then took the name of National Society of Surgery in 1875. It was in 1935 that it took the name of Academy of Surgery, then adopted its current name in 1997.

One of its missions is moral responsibility in everything related to surgery, being the guardian of its history, the guarantor of its ethics and the witness of its evolution.

This year, the National Academy of Surgery integrated for the first time as an associate member oral surgeons. This is recognition of our discipline as a full-fledged surgical specialty that ignores our dual origin, whether medical or odontological. This is a real proof of openness and realism on the part of this great institution and its current members.

I invite you to consult the documents on the academy's website (called "e-mémoires") made available to all health professionals; you will thus find recommendations, therapeutic updates or new articles which aim to advance Surgery. These documents are of course still few on oral surgery itself.

They will nevertheless allow you to better understand the other missions of this institution: careful and rigorous evaluation of the development of the technical aspects of the surgical art and their changes (some articles are very old but allow you to better understand the advances in medicine and surgery [1]), control of the conditions of the specific practice of surgery and assessment of the training and recruitment of surgeons. It is also very appreciable to see that the academy gives a very large place to the definitions of good surgical practices, making it possible to limit the loss experience of surgical acts in per and/or immediate postoperative and long term, while being realistic on the fact that this loss experience is inherent in our discipline.

The National Academy of Surgery is also open internationally and regularly participates in international days or forums. Finally, the Academy also wishes to promote clinical and basic research carried out by surgeons. To this end, it is organizing a Clinical Surgical Research Day on Friday, December 3, 2021. During this session, five prizes will be awarded to the best work presented (fundamental research applied to surgery, surgical technological innovation, clinical research, educational innovation in surgery and risk prevention in surgery). So there is still time to apply, the application deadline is November 3, 2021. So be creative and use your pens!

\section{Reference}

1. Tuffier M. Intervention chirurgicale directe dans un anévrysme de la crosse de l'aorte. Ligature du sac. Bull Mem Soc Chir Paris 1902;28:326-344.

\footnotetext{
*Correspondence: laurent.devoize@uca.fr
} 